\begin{tabular}{l|c|c}
\hline $\begin{array}{c}\text { ISSN 2525-4812 (versão online) } \\
\text { ISSN 2238-7641 (versão impressa) } \\
\text { http://www.revistaterceiramargem.com/ } \\
\text { index.php/terceiramargem/index }\end{array}$ & $\begin{array}{c}\text { Recebido em: 3/3/2020 } \\
\text { Aprovado em: } 7 / 2 / 2020 \\
\text { Período de publicação: jan., } 2021\end{array}$ & $\begin{array}{c}\text { Revista Terceira } \\
\text { Margem Amazônia } \\
(\mathrm{v} .6 \cdot \text { n. especial 16 • Jan. 2021) }\end{array}$ \\
\hline Como citar o artigo: \\
$\begin{array}{l}\text { SANTOS, A. C; BRITO, A. P. S. B.; NEVES, S. F. A importância da indústria de biocosméticos para o desempenho econômico } \\
\text { do estado do Amazonas. Revista Terceira Margem Amazônia. v. 6, n. especial 16, p. 105-125, 2021. DOI: http://dx.doi.or- } \\
\text { g/10.36882/2525-4812.2021v6i16.ed.esp.p105-125 }\end{array}$ \\
\hline
\end{tabular}

\title{
A IMPORTÂNCIA DA INDÚSTRIA DE BIOCOSMÉTICOS PARA O DESEMPENHO ECONÔMICO DO ESTADO DO AMAZONAS
}

\author{
Alessandro Carvalho dos Santos ${ }^{l}$ \\ Ana Paula de Souza Barros de Brito ${ }^{2}$ \\ Salomão Franco Neves ${ }^{3}$
}

\begin{abstract}
Resumo: Esta pesquisa teve como objetivo investigar as implicações da produção de biocosméticos para o desempenho econômico do estado do Amazonas. Para tal, de forma específica, foi descrita a produção de biocosméticos e verificada a sua relevância na composição da indústria de transformação amazonense. Isto posto, de forma a viabilizar os objetivos propostos por esta pesquisa, foram utilizados dados oriundos do Instituto Brasileiro de Geografia e Estatística (IBGE), bem como da Superintendência da Zona Franca de Manaus (Suframa), pertinentes ao período de tempo estabelecido entre 2010 e 2015. A partir desses foi ponderada a dimensão da contribuição da indústria de biocosméticos na esfera econômica amazonense, mostrando, por meio de gráficos e tabelas, o resultado da atuação desta no cenário regional. Quanto aos resultados, foi percebido que a bioindústria de cosméticos no Amazonas ainda apresenta dificuldades na produção em larga escala, consequência da baixa produtividade das matérias-primas utilizadas, visto que o cultivo desses insumos apresenta sazonalidade, como é o caso do açaí, da castanha e da copaíba. Além disso, a logística de transporte na região amazônica é outro fator que desincentiva a instalação de nova matriz econômica no estado por causa da dificuldade de escoamento da matéria-prima para a indústria de biocosméticos.
\end{abstract}

Palavras-chave: indústria, biocosméticos, desempenho econômico.

\footnotetext{
Bolsista de Iniciação Científica, Paic/Fapeam/Embrapa Amazônia Ocidental, Manaus, AM. E-mail: alessandrocarvalho1999@gmail.com

(D) https://orcid.org/0000-0003-0116-7155

2 Graduanda em Ciências Econômicas.Universidade Federal do Amazonas (Ufam), Manaus, AM. E-mail: apaulabriito@gmail.com.

(D) https://orcid.org/0000-0002-6901-0069

3 Economista, D. Sc. em Desenvolvimento Sustentável, professor da Universidade Federal do Amazonas, Manaus, AM. E-mail: salomao@ufam.edu.br

(D) https://orcid.org/0000-0003-1853-3940
} 


\title{
THE IMPORTANCE OF THE BIOCOSMETICS INDUSTRY FOR THE ECONOMIC PERFORMANCE OF AMAZONAS STATE, BRAZIL
}

\begin{abstract}
This research aimed to investigate the implications of biocosmetics production in economic performance of Amazonas State, Brazil. In a specific way, the biocosmetics production was described and the relevance in state's manufacturing industry composition was verified. That said, in order to make viable the objectives proposed, data from the Brazilian Institute of Geography and Statistics (IBGE), as well as from the Manaus Free Trade Zone Superintendence - Suframa, on 2010-2015 years, were used. From these, the biocosmetics industry contribution in state's economics was verified, showing through graphs and tables the performance results in the regional scenario. As for the results, it was noticed that the cosmetics bioindustry in Amazonas still presents difficulties in large-scale production, as consequence of low productivity of the raw materials used since the cultivation of these inputs presents seasonality, as is the case of açaí, chestnut and copaiba. In addition, transport logistics is another factor that discourages the installation of a new economic matrix in the state, due to raw material allocation difficulties on biocosmetics production process.
\end{abstract}

Keywords: industry, biocosmetics, economic performance.

\section{Introdução}

A tendência de busca por um padrão de consumo amparado em princípios do desenvolvimento sustentável ganhou força ao longo das últimas décadas do século XX, e no início do segundo milênio isso não é diferente. Como consequência, as estratégias de fabricação dos produtos naturais, entendidos por mercadorias com composição majoritária ou total de materiais oriundos do meio ambiente, modificam-se de acordo com a mudança de comportamento dos consumidores, que se mostram cada vez mais interessados em informações sobre procedência, metodologia de fabricação e o impacto desses fatores sobre a natureza.

A necessidade de se ter uma produção economicamente sustentada e ambientalmente sustentável impulsionou a bioindústria e, consequentemente, a indústria de cosméticos, com oportunidades de trabalho em torno dos 5,6 milhões em 2017, conforme o anuário 2018 da Associação Brasileira da Indústria de Higiene Pessoal, Perfumaria e Cosméticos (ABIHPEC, 2018).

No cenário nacional estima-se que o setor de cosméticos gere algo em torno de 3,6 milhões de empregos diretos e indiretos. No ano de 2011, o Brasil passou os EUA, tornando-se o primeiro do mundo no mercado de perfumaria e o segundo país que mais consome produtos na área de cosméticos no mundo (BARATA, 2012). A expansão do parque industrial brasileiro provocou uma grande infraestrutura de fornecedores de insumos capaz de competir no mercado internacional, destaca-se a força da "biodiversidade amazônica" na opinião pública internacional que repercute positivamente na valorização dos bioprodutos (LYRIO et al., 2011).

A produção de biocosméticos tem no uso de matéria-prima amazônica a capacidade de desenvolver diferentes insumos incorporados aos artigos cosméticos, que por sua vez podem ser utilizados para diversos fins dentro dos produtos cosméticos ou em outros produtos. Revilla (2001), em um de seus estudos, cita cerca de 70 espécies vegetais amazônicas de grande potencial econômico que podem ser utilizadas para fins cosméticos. Porém, grande parte delas não possui informações oficiais perante a Agência Nacional de Vigilância Sanitária (Anvisa), órgão regulamentador do setor dentro do País, dificultando a entrada de investimentos específicos para o setor. 
No aspecto regional, a Amazônia apresenta um cenário econômico propício para produção dos biocosméticos. O mercado oriundo da biodiversidade amazônica está em plena expansão, diversas matérias-primas nativas indicam a possibilidade de desenvolvimento para novos bioprodutos em destaque para setores de cosméticos (MIGUEL, 2009). Os setores de extratos vegetais e concentrados para a fabricação de bebidas não alcoólicas têm funcionado como verdadeira alavanca para a bioindústria no estado do Amazonas, que no ano de 2008 obteve um faturamento nesse setor de aproximadamente US\$ 100 milhões no Polo Industrial de Manaus (PIM) (SUFRAMA, 2009).

A diversidade da flora amazônica fez com que efetivamente seus insumos passassem a ser inseridos na aplicação cosmética. Como consequência, a atividade bioindustrial na região trouxe implicações de cunho social, traduzidas em emprego e renda, além de maior enfoque nas questões envolvendo atividades produtivas e a natureza. Logo, essa atividade surge como uma boa alternativa para o desenvolvimento econômico do estado. A bioindústria de cosméticos, com potencial econômico concentrado na floresta amazônica e em seus produtos, demonstra a importância de se utilizar a matéria-prima regional como um dos pilares para o desenvolvimento socioeconômico da região.

As exigências para uma produção com enfoque na relação entre sustentabilidade e eficácia produtiva foram o assunto de diversas pesquisas relacionadas ao setor bioindustrial em nível mundial. No caso brasileiro, as operações logísticas têm recebido grandes investimentos visando a seu aprimoramento (FLEURY et al., 2000). Nesse sentido, as interações industriais se modificaram seguindo a tendência que propõe substituir produtos sintéticos por naturais. Tal mudança de hábitos impulsionou a criação de novas bioindústrias e incentivou a adequação das já atuantes, com o aperfeiçoamento de novas linhas de bioprodutos (LOPES; CAVALCANTE, 2010).

A partir da contribuição de autores como Revilla (2001), Miguel (2009) e Lopes e Cavalcante (2010) é percebida uma relação direta entre a bioindústria brasileira, em especial nos setores alimentício e cosmético, e a matéria-prima proveniente da Amazônia. O fornecimento de insumos, no caso da indústria biocosmética, com relação aos produtos amazônicos ganha cada vez mais espaço no mercado de higiene pessoal, perfumaria e cosméticos (HPPC).

Ademais, vale ressaltar a importância dessa atividade para o crescimento econômico na forma de geração de emprego e renda, o que se observa em diversas comunidades, principalmente no interior do estado do Amazonas. Estas, a partir do momento em que são inseridas como fornecedoras de matéria-prima para as bioindústrias de cosméticos, principalmente as do PIM, contribuem potencialmente para o aumento da atividade econômica no estado, como já pode ser visto nos municípios de Maués, Novo Airão e Manaquiri, onde já acontece a fabricação de biocosméticos (LOPES 2011; BARATA, 2012).

Contudo, embora a matéria-prima proveniente da Amazônia seja abundantemente utilizada pela indústria biocosmética, ainda há carência de estudos voltados para o desempenho da bioindústria de cosméticos no estado do Amazonas. É preciso saber identificar as potencialidades e as dificuldades de se desenvolver a bioindústria na região, de modo que essa pesquisa se faz necessária, além de servir como referência para futuros estudos de mesma temática. 
Logo, este artigo tem o objetivo de investigar as implicações da produção de biocosméticos para o desempenho econômico do estado do Amazonas. Para tal será descrita a sua produção na área estudada e verificada a relevância de sua produção na composição da indústria de transformação amazonense.

\section{Revisão de Literatura}

\section{Definição de Indústria}

Para a elaboração deste estudo utilizou-se o conceito de Indústria como referência para a integração de diferentes abordagens dentro da indústria cosmetológica, destacando as heterogeneidades produtivas como marco dessa indústria. De acordo com Varian (2006), a indústria traduz-se como a atividade econômica secundária que considera o processo produtivo e todas as suas etapas. A indústria descrita por Marshall (1982), no entanto, engloba as atividades primária (extrativa) e terciária (comercial), conceituando indústria como um conjunto de empresas que elaboram produtos iguais ou semelhantes, ou ainda, produtos distintos baseados no mesmo insumo, que tenham por objetivo a produção e venda dessas mercadorias no mercado de bens e serviços. Esta será a conceituação relevante para este estudo.

Os setores industriais e de prestação de serviços sustentam a economia brasileira. A classificação da atividade industrial varia conforme seu foco de atuação. Na perspectiva deste estudo, é necessário discorrer sobre a atuação da indústria de transformação, pois nela é onde se compreendem as atividades de transformação química exercida pela indústria química, subsetor importante da indústria transformadora, que compreende as manipulações praticadas pela indústria de cosméticos, foco desta pesquisa.

\section{Indústria de Transformação}

O conceito de indústria de transformação apresentado pela Classificação Nacional das Atividades Econômicas (CNAE) do Instituto Brasileiro de Geografia e Estatística (IBGE), descreve esse setor industrial como o responsável pela:

\footnotetext{
"transformação física, química e biológica de materiais, substâncias e componentes, com a finalidade de obterem produtos novos. Os materiais, substâncias e componentes são insumos produzidos nas atividades agrícolas, florestais, de mineração, da pesca e produtos de outras atividades industriais" (IBGE, 2015).
}

Ademais, a indústria transformadora não somente faz a transformação dos insumos em novos produtos, mas a renovação e reconstituição desses produtos. Além disso, os novos produtos de um ramo industrial podem estar prontos para consumo ou semiacabados para serem usados como matéria-prima em outro estabelecimento da indústria de transformação, como, por exemplo: a produção do açaí, que servirá de alimento quando tratado como bem de consumo final ou matéria-prima para a produção de cosméticos naturais. 
Conforme a Figura 1, no Brasil, o setor químico é o terceiro maior da indústria de transformação. A indústria química equivale a um subsetor essencial da intitulada indústria de processos, e corresponde a $10,8 \%$ do PIB da indústria de transformação, perdendo lugar somente para o setor de alimentos e bebidas e produtos derivados do petróleo e biocombustíveis, que correspondem, respectivamente, a $22 \%$ e $15,7 \%$ do valor total do PIB nessa indústria transformadora.

Figura 1. Participação da indústria química na indústria de transformação (em \% sobre o PIB industrial).

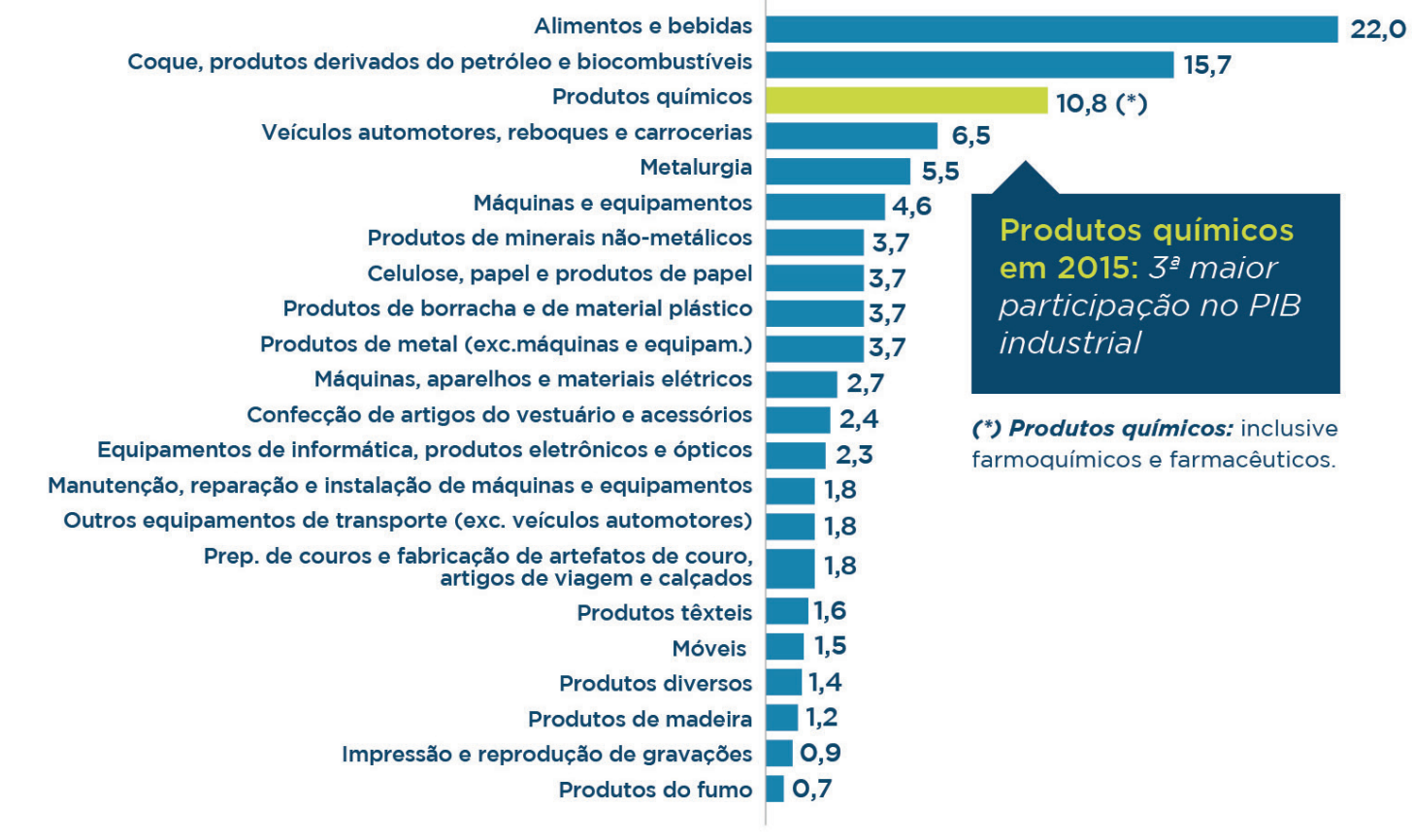

Nota: De 1992 a 1994, a química ocupou a 1ª posição; de 1995 a 2004 ficou em 2a; de 2005 a 2007, em 3ª de 2009 a 2013, em 4a; e em 2014 subiu novamente para a $3^{\mathrm{a}}$ posição.

Fonte: IBGE (2015) - PIA Empresas Unidade de Investigação: Unidade local industrial.

Nos últimos anos, o setor químico apresentou forte crescimento, isso se dá em razão de a indústria química possuir interação com praticamente todos os setores da atividade econômica. Os artigos produzidos por esse setor industrial auxiliam desde o desenvolvimento de novas tecnologias de informação até a produção e distribuição de alimentos, serviços de manutenção ao ambiente, saúde e bem-estar, o que exige desenvolvimento contínuo do setor motivado por um conjunto de interesses de diversas áreas da economia.

No Brasil, o IBGE, juntamente com a Associação Brasileira da Indústria Química (Abiquim), definiu uma CNAE como instrumento de padronização nacional dos códigos de atividades econômicas, enquadrando-as em classes e subclasses associadas. Após a definição dos critérios de classificação, na seção C das Indústrias de Transformação, contemplados nas divisões 20 e 21 da CNAE, considera-se indústria química aquela que enquadra os segmentos abaixo. 


\section{Classificação CNAE quanto a indústria química}

\section{Fabricação de Produtos Químicos}

20.1 Fabricação de Produtos Químicos Inorgânicos

20.2 Fabricação de Produtos Químicos Orgânicos

20.3 Fabricação de Resina e Elastômeros

20.4 Fabricação de Fibras Artificiais e Sintéticas

20.5 Fabricação de Defensivos Agrícolas e Defensivos e Desinfetantes Domissanitários

20.6 Fabricação de Sabões, Detergentes, Produtos de Limpeza, Cosméticos, Produtos de Perfumaria e de Higiene Pessoal

20.7 Fabricação de Tintas, Vernizes, Esmaltes, Lacas e Produtos Afins

20.8 Fabricação de Produtos e Preparados Químicos Diversos

21. Fabricação de Produtos Farmoquímicos e Farmacêuticos

21.1 Fabricação de Produtos Farmoquímicos

21.2 Fabricação de Produtos Farmacêuticos

Fonte: IBGE - CNAE Classificação Nacional das Atividades Econômicas (2015b).

\section{Indústria de HPPC}

O setor cosmético é parte integrante da indústria química. O que se entende como indústria de cosméticos é na realidade um segmento que engloba os setores de perfumaria, higiene pessoal e limpeza (GARCIA; FURTADO, 2002).

A Resolução RDC 211 da Anvisa, de 14 de julho de 2005, caracteriza produtos de higiene pessoal, perfumaria e cosméticos como: "preparações constituídas por substâncias naturais ou sintéticas de uso externo nas diversas partes do corpo humano, pele, sistema capilar, unhas, lábios, órgãos genitais externos, dentes e membranas mucosas da cavidade oral, com o objetivo exclusivo ou principal de limpá-los, perfumá-los, alterar sua aparência e/ou corrigir odores corporais e/ou protegê-los ou mantê-los em bom estado".

A atuação do setor, no Brasil, é acompanhada por duas entidades principais: o Instituto de Pesquisa Internacional Euromonitor, como provedor independente de pesquisas de mercado, analisando as interações de mais de 80 países do mundo, e a ABIHPEC, que atua na defesa dos interesses do setor nas diversas esferas públicas, realiza o acompanhamento estatístico do setor e acompanha toda a legislação e normas específicas aplicáveis, visando não somente à regularidade, mas também à evolução da indústria e sua integração ao mercado mundial.

Segundo a ABIHPEC (2006), a indústria brasileira de HPPC vem apresentando crescimento significativo nos últimos anos, tendo passado de um faturamento de R \$ 8,3 bilhões em 2001 para R \$ 15,4 bilhões em 2005. Segundo a entidade, entre os fatores determinantes desse crescimento estão: a participação da mulher brasileira no mercado de trabalho, o aumento da expectativa de vida, lançamentos constantes de produtos, uma cultura cada vez mais direcionada à saúde e bem-estar e a participação crescente do homem no consumo de produtos de HPPC.

Dados da Abiquim e associações dos segmentos específicos mostram que o faturamento líquido da indústria química brasileira, em 2017, foi estimado em US\$ 119,6 bilhões, sendo US\$ 12,4 bilhões provenientes da indústria de HPPC. Conforme Garcia e Furtado (2002), esse setor 
industrial se caracteriza pela necessidade de pesquisas contínuas para o desenvolvimento de inovações no mercado de produtos e a introdução de novos insumos na atividade produtiva.

Existem diferentes terminologias para diferenciar os cosméticos naturais e orgânicos, pois cada um apresenta em sua composição características próprias, quer seja na sua formulação, quer seja nos insumos. Os cosméticos orgânicos contêm em sua composição 95\% de matérias-primas certificadas orgânicas e 5\% de matérias-primas naturais. Por outro lado, os cosméticos naturais ou biocosméticos têm em sua formulação $5 \%$ de matérias-primas certificadas orgânicas, e o restante, $95 \%$, é composto de matérias-primas naturais não certificadas, desde que sejam naturais. Além disso, os cosméticos naturais, ou biocosméticos, são biodegradáveis, o que não afeta o meio ambiente, e são menos propensos a causar alergias e efeitos colaterais (LOPES; CAVALCANTE, 2010; LYRIO et al., 2011).

Com a existência dos movimentos de preservação ao meio ambiente, há um grupo de consumidores que buscam por produtos de procedência natural e que sejam livres de agrotóxicos e de produtos químicos, ou seja, produtos com alto apelo ecológico, cultivados com rígido controle de qualidade. Isto é, estabelecidos pelas organizações nacionais e internacionais tornando-se alternativa capaz de conquistar uma maior parcela do público preocupado com meio ambiente e saúde (LOPES; CAVALCANTE, 2010; LOPES, 2011).

No cenário mundial estima-se que o mercado de cosméticos naturais, em 2010, proporcionou um ganho de cerca de US\$ 10 bilhões, que representou, no mesmo período, 2,5\% do mercado global de produtos de higiene e limpeza. Além disso, outros indicadores apontam um cenário ainda mais promissor, movimentação de mais de U\$ 23 bilhões no segmento, registrando um aumento de $15 \%$ comparado ao ano anterior (MIGUEL, 2012).

Os países asiáticos e do Pacífico lideram o consumo de produtos naturais, todavia, o país que concentra o maior número de vendas dessas mercadorias são os EUA, onde o mercado desenvolveu, no ano de 2010, cerca de U\$ 3,8 milhões, crescendo $12 \%$ em relação ao ano anterior, e com perspectivas de crescimento equivalente a U\$ 6,8 bilhões em 2015. O aumento do consumo de cosméticos naturais e orgânicos nos países da Europa, nos EUA e no Japão está interligado às tendências que ocorreram desde meados da década de 1990, como o aumento de consumo de alimentos orgânicos (MIGUEL, 2012).

No Brasil, os produtos naturais ainda têm pouco destaque se comparados ao volume total de consumo da indústria de cosméticos do Brasil, entretanto a tendência é de crescimento no mercado desse segmento, a expansão está atrelada a diversos fatores, destacando-se: o crescimento do uso de ingredientes desenvolvidos a partir da biodiversidade, principalmente de origem amazônica; e a crescente entrada de empresas nacionais nesse segmento de mercado, por meio da inserção de produtos naturais em seu portfólio. Diante disso, a falta de uma legislação específica nacional que regulamente os biocosméticos permite que empresas divulguem produtos de origem não natural como se fossem cosméticos naturais (MIGUEL, 2012).

O mercado de cosméticos naturais tem crescido anualmente em torno de $11 \%$, o que representa uma fatia de $18 \%$ a $22 \%$ do mercado de cosméticos brasileiro, uma porcentagem elevada em comparação a dos EUA, que chega de 3\% a 4\%, e no mercado europeu, $2 \%$ a $3 \%$. O fator que impulsiona esse mercado no Brasil é sua biodiversidade, já que o País detém cerca de $20 \%$ 
da biodiversidade do mundo, onde estima-se que existem 10 mil espécies de plantas candidatas à matéria-prima na área da saúde, dentre elas 135 espécies que já têm princípios verificados para o uso na área cosmética (ISAAC, 2016).

O cenário favorável a esse segmento de mercado impulsionado no Brasil corresponde a diversos aspectos, tendo como exemplos a pesquisa científica de campo e o desenvolvimento tecnológico acelerado, que desenvolve insumos inovadores e únicos que contribuem para o avanço de novas formulações cosméticas com maior apelo ambiental. Esses aspectos também fazem com que empresas adotem técnicas de fabricação mais sustentáveis, ampliando o uso de matérias-primas naturais que contribuam para a produção e certificação de cosméticos com selos orgânicos (ISAAC, 2016).

A entrada da indústria brasileira no segmento de biocosméticos tem como característica a estratégia de inserção no mercado internacional, essa tendência é traduzida pela oportunidade para o desenvolvimento de produtos finais, como também para intermediários e processadores de matéria-prima, explorando seu ponto forte, que é a biodiversidade. No ano de 2008, estudos mostraram que os consumidores ecológicos estavam dispostos a pagar até $15 \%$ a mais por cosméticos naturais (LOPES; CAVALCANTE, 2010; MIGUEL, 2012).

No cenário local, a produção de biocosméticos dá-se principalmente por intermédio da rica diversidade da região. A indústria à base de produtos e insumos amazônicos já é uma realidade no estado do Amazonas, diante da extração e processamento de óleos, ervas, frutos e resinas para aplicação tanto na área de fármacos como na cosmetológica. Esse fato é observado nos cenários nacional e internacional da bioindústria, principalmente no último, que busca na região plantas amazônicas ou domesticadas na região, essências e insumos que possibilitem a produção em larga escala de biocosméticos e de fitoterápicos (LIMA, 2011).

A produção de biocosméticos no Amazonas caminha a passos lentos, sobretudo devido a dificuldades como a disponibilidade de matérias-primas, logística entre as comunidades produtoras e empresas, a aquisição de embalagens ou a disponibilidade de mão de obra especializada para a indústria. As empresas locais Gotas da Amazônia, Pharmakos D’Amazônia e Amazongreen têm, de forma independente, sua cadeia produtiva de insumos, constituindo, assim, um desafio para as bioindústrias locais (LIMA, 2011).

Na cadeia produtiva dos fitoterápicos e cosméticos local observam-se quatro tipos de segmentos: o fornecedor de matéria-prima, onde se encontra o extrativista e/ou agricultor; usinas de extração de óleo bruto, onde é extraído óleo de forma artesanal; indústria de refinamento de óleos vegetais, que trabalha na elaboração de produtos naturais, como matéria-prima para utilização na indústria de cosméticos, alimentícia, farmacêutica e fitofármacos; e a indústria de fitoterápicos e cosméticos, onde é desenvolvido e fabricado o produto final (LOPES; CAVALCANTE, 2010).

A tendência, nas últimas décadas, tem sido a busca por produtos de origem orgânica ou natural, que fomenta novas indústrias. Dentre os segmentos emergentes surge a bioindústria, que vem ganhando força, despontando a partir das mudanças estruturais, ambientais e tecnológicas demandadas pelo mercado consumidor. Diante disso, após a análise realizada por Porter (1986), essa nova indústria se enquadrou na categoria de "indústria emergente", que se caracterizou por 
uma parcela da produção e serviços recentemente criada por inovações tecnológicas, a partir do surgimento de novas necessidades dos consumidores ou novas oportunidades do mercado (JUDICE; BAÊTA, 2002).

Existem inúmeros segmentos da bioindústria, dentre eles destaca-se a bioindústria de cosméticos, que envolve múltiplas formas de atuação e é representada por empresas com estruturas físicas variadas, que vão desde empresas locais, geralmente micro e pequenas empresas, a empresas líderes no cenário nacional no segmento, como, por exemplo, Natura e O Boticário, chegando a empresas transnacionais, como a Body Shop (inglesa) e L'Oréal (francesa), que em geral detêm algumas das etapas produtivas dos biocosméticos ou todas as etapas de produção, que vão desde o processamento das matérias-primas até a finalização dos bioprodutos (MIGUEL, 2009; LOPES, 2011).

No ano de 2006, existiam no Brasil 1.596 empresas atuando no setor de cosméticos, das quais $89,9 \%$ são empresas de micro, pequeno e médio portes. As demais empresas são formadas por 15 corporações de grande porte, com receita líquida acima de R $\$ 100$ milhões, que simbolizam $71 \%$ do total desse segmento. A região onde se encontra o maior número de empresas é o Sudeste, totalizando 1.003 (SEBRAE; ESPM, 2008).

As empresas de médio e grande portes são as mais consolidadas no contexto da bioindústria, em geral são mais estruturadas e têm arranjos produtivos mais complexos, como a Natura, Beraca/Brasmazon e Croda. As bioindústrias estão além de seus polos urbano-industriais, como ocorre em Belém e Manaus, onde a maioria das matérias-primas é proveniente de comunidades localizadas nas regiões metropolitanas de suas capitais. No estado do Pará, especialmente em Belém, existe uma centralidade das principais indústrias e usinas de beneficiamento e processamento de matérias-primas da Amazônia, que atuam de forma articulada para a produção agroindustrial, com a produção de frutas nativas/adaptadas e de castanhas, que são insumos destinados à produção de inúmeros bioprodutos (MIGUEL, 2009).

Ademais, no estado do Amazonas, os empreendimentos de pequeno porte, a exemplo da Pronatus do Amazonas, a Pharmakos da Amazônia, a Ervativa, a Insumos da Amazônia, entre outras, estão em processo de franca expansão da sua produção. Além disso, todas apresentam uma característica em comum, o forte vínculo com as instituições de ensino e pesquisa locais. Esse diferencial tem sido notório devido à cooperação constante para o processo de inovações incrementais e criação de bioprodutos, como também à ajuda das instituições públicas para a captação de recursos de instituições, tais como Serviço Brasileiro de Apoio às Micro e Pequenas Empresas (Sebrae), Banco da Amazônia (Basa), Fundação de Amparo e Desenvolvimento da Pesquisa (Fadesp), o que resulta na ampliação da participação dessas empresas no mercado de biocosméticos (MIGUEL, 2009).

No cenário regional, a bioindústria sobressai, principalmente, devido à biodiversidade amazônica, por meio da extensa capacidade de insumos regionais que potencializa a produção de novos bioprodutos, o processamento desses insumos é, principalmente, por meio da extração de óleos essenciais, como: óleo de andiroba, castanha, cupuaçu, buriti, muru-muru, copaíba, ucuúba, semente de maracujá, entre outros. A origem dos insumos para a produção é oriunda das comunidades extrativistas e ribeirinhas. Esse arranjo produtivo pode contribuir para o desenvolvimento 
socioambiental dessas regiões, uma vez que a extração é realizada de forma sustentável e sem prejudicar a natureza (SEBRAE; ESPM, 2008).

No aspecto local, após a aprovação do Processo Produtivo Básico 482 (PPB) de 2008, possibilitou-se alavancar ainda mais a produção de cosméticos no Amazonas. A Superintendência da Zona Franca de Manaus (Suframa) observou a possibilidade de investimentos nesse setor, que potencializou o aumento da produção e diversificação da indústria de cosméticos, da qual já possui pequeno polo de produção no PIM principalmente para a produção de óleos essenciais como: andiroba, castanha, cupuaçu e buriti (BASTOS et al., 2012).

No Amazonas, a extração das matérias-primas encontra-se distribuída em diversas comunidades do interior do estado, que possibilita o acréscimo na renda dos produtores por meio das miniusinas de beneficiamento. As bioindústrias de cosméticos locais vêm destacando-se com a consolidação de sua marca regional e já reconhecida no mercado, como, por exemplo: Pharmakos da Amazônia, Amazon Ervas e Pronatus, que fabricam produtos com componentes de essência ou insumo da biodiversidade local, permitindo, por isso, o uso da marca "Amazônia" (BASTOS et al., 2012).

No aspecto econômico, a Suframa (2009) ressalta que o mercado de medicamentos e cosméticos foi avaliado em torno de 25 bilhões de dólares, em sua composição os produtos fabricados detinham $25 \%$ de princípios ativos naturais. Os setores de extratos vegetais, concentrados e compostos, têm funcionado como meio para a expansão da cadeia bioindustrial no estado do Amazonas e de toda a região, o destaque para esse setor foi seu faturamento, que rendeu ao PIM, em 2008, o valor de mais de U\$ 100 milhões de dólares (SUFRAMA, 2009; LOPES, 2011).

\section{Metodologia}

A presente pesquisa fundamenta-se como pesquisa bibliográfica, elaborando-se uma revisão de literatura relacionada ao tema em questão. No que se refere aos materiais utilizados estão artigos sobre pesquisas bioindustriais, os biocosméticos, e dados oficiais de órgãos especializados, como a ABIHPEC.

Pretende-se analisar o desempenho da indústria de transformação amazonense a partir das variações verificadas nos insumos e produtos previamente selecionados. Nesse sentido, açaí, castanha e óleo de copaíba foram os escolhidos para a caracterização dos insumos amazônicos. Da mesma forma foram adotados três produtos entre os itens de HPPC produzidos no PIM como representantes do segmento cosmético do setor químico do PIM (Tabela 1).

Tabela 1. Produtos de higiene pessoal, perfumaria e cosméticos (HPPC) produzidos no Polo Industrial de Manaus (PIM), para a caracterização do segmento cosmético.

\begin{tabular}{|ll} 
NCM do produto & \multicolumn{1}{c}{ Descrição do produto } \\
33049910 & Cremes de beleza, cremes nutritivos e loções tônicas \\
33051000 & Xampus \\
33073000 & Sais perfumados e outras preparações para banhos
\end{tabular}

Fonte: Suframa (2019). 
Quanto ao cumprimento dos objetivos específicos deste artigo foram utilizados dados disponibilizados pela Suframa, considerando as informações sobre quantidade produzida e quantidade vendida para cada um dos produtos mencionados no Tabela 1, bem como dados regionais do IBGE, com referenciais da produção da extração e silvicultura (PEVS/IBGE), no período estabelecido entre 2010 e 2015, considerando também a quantidade produzida e o valor da produção dos insumos selecionados.

A partir dos dados levantados explorou-se a correlação entre a produção dos insumos regionais para cada um dos produtos, a fim de determinar o nível de correlação entre eles; ponderou-se, também, a dimensão da contribuição da indústria de biocosméticos na esfera econômica amazonense, mostrando por meio de tabelas e gráficos trabalhados na ferramenta Excel o resultado da atuação dessa indústria no cenário regional.

\section{Resultados e Discussões}

A crescente demanda por produtos naturais promoveu, nas últimas décadas, a modernidade do agronegócio e a inserção de insumos amazônicos em novos nichos dos mercados nacional e internacional. Além disso, grandes indústrias nacionais e transnacionais, como O Boticário, Colgate-Palmolive, L'Oréal e Natura, introduziram em seu portfólio diversos produtos com princípios ativos provenientes de insumos amazônicos, o que pode justificar o aumento, ao longo dos anos, da produção de diversas matérias-primas da região, entre elas o açaí, a castanha e o óleo de copaíba.

A partir de meados da década de 1990, a polpa de açaí passou a ser comercializada em outras regiões, estados da região Nordeste, Centro-Oeste, Sudeste e Sul do País, nesse período já era demandada uma quantidade expressiva da polpa e produtos oriundos do açaí. Em 2011, o fruto obteve um acréscimo expressivo em sua produção, cerca de 73,1\% com relação ao ano anterior, produzindo no País cerca de 215 mil toneladas do fruto. Todos os estados produtores apresentaram aumento da produção, sendo o mais significante o do Amazonas, que produziu $89.480 \mathrm{t}$ nesse mesmo ano e passou a ocupar o $1^{\circ}$ lugar dos 20 maiores municípios produtores de açaí do País, com o município de Codajás (IBGE, 2019).

Em 2012, a produção total de açaí apresentou a queda mais drástica, de 7,3\%, em decorrência da grande cheia registrada no estado do Amazonas, que reduziu a produção total do País a 199.116 t. No ano de 2015, a produção nacional de açaí já correspondia a 216 t, estimadas em R\$ 480 milhões. A região Norte já representava 93,1\% do extrativismo vegetal não madeireiro de todo o Brasil com a produção do fruto, somente o Amazonas era o responsável por $30 \%$ dessa produção, avaliada em R\$116.722 milhões, como demonstra a Figura 2.

Os principais estados produtores e consumidores de açaí permanecem sendo os estados da região Norte, especialmente o estado do Pará, onde o fruto é consumido principalmente como bebida, obtida por meio da adição de água durante o processamento dos frutos. Diversas formas de apresentação têm surgido além da sua forma tradicional para consumo, o açaí tem mostrado multiplicidade de uso na indústria de corantes e bebidas. Por meio de seu corante natural (antocianina), o açaí é empregado nas indústrias farmacêutica e cosmética como xampus, cremes, condicionadores e cremes dentais. 
Figura 2. A evolução da produção de açaí no estado do Amazonas.

\section{Quantidade produzida e valor do produto da extração do açaí extrativo}

no Amazonas - 2010 a 2015

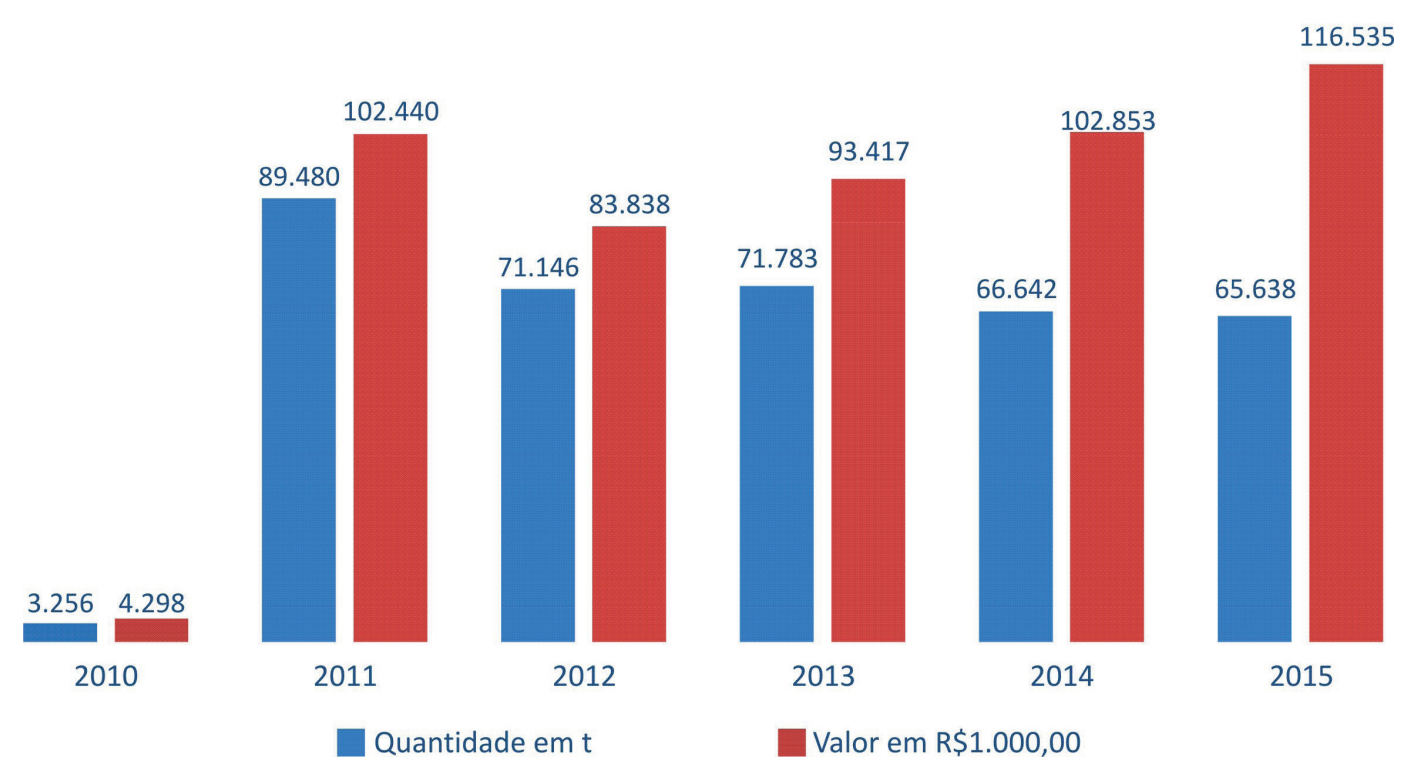

Fonte: Elaboração própria, utilizando dados do IBGE (2019).

A castanha, um fruto também extraído da região amazônica, assegura renda e trabalho às comunidades ribeirinhas e extrativistas dos estados produtores. Ela é comercializada de diversas formas, das quais destacam-se: in natura, em forma de óleo e a casca, que é aproveitada para o artesanato.

O Amazonas liderou a produção nacional na geração desse insumo nos anos de 2010 e 2011, o município que obteve a maior produção foi Beruri, com 6.600 e 6.100 toneladas produzidas nos anos supracitados. Além disso, outros municípios do estado também produzem a matéria-prima como: Lábrea, Boca do Acre, Coari, Humaitá, Tefé, Codajás e Manicoré (IBGE, 2019).

Em 2012, ocasionada pela baixa produtividade no estado do Amazonas e pelo baixo preço praticado no mercado, houve uma retração de $7,8 \%$ da produção nacional comparada ao ano anterior. O município que mais produziu no estado foi Beruri, com produção de $1.500 \mathrm{t}$, e o valor da produção amazonense foi estimado em R 20.715 mil (IBGE, 2019).

Nos anos posteriores, entre 2013 e 2015, o estado do Amazonas permanece na segunda colocação na produção nacional de castanha, ficando atrás apenas do Acre. A produção média foi de 12.919 t e o valor da produção média foi R\$ 28.190 mil, potencializando esse insumo para a fabricação de novos produtos (Figura 3). 
Figura 3. A evolução da produção de castanha no estado do Amazonas.

\section{Quantidade produzida e valor do produto da extração da} castanha-do-brasil no Amazonas - 2010 a 2015

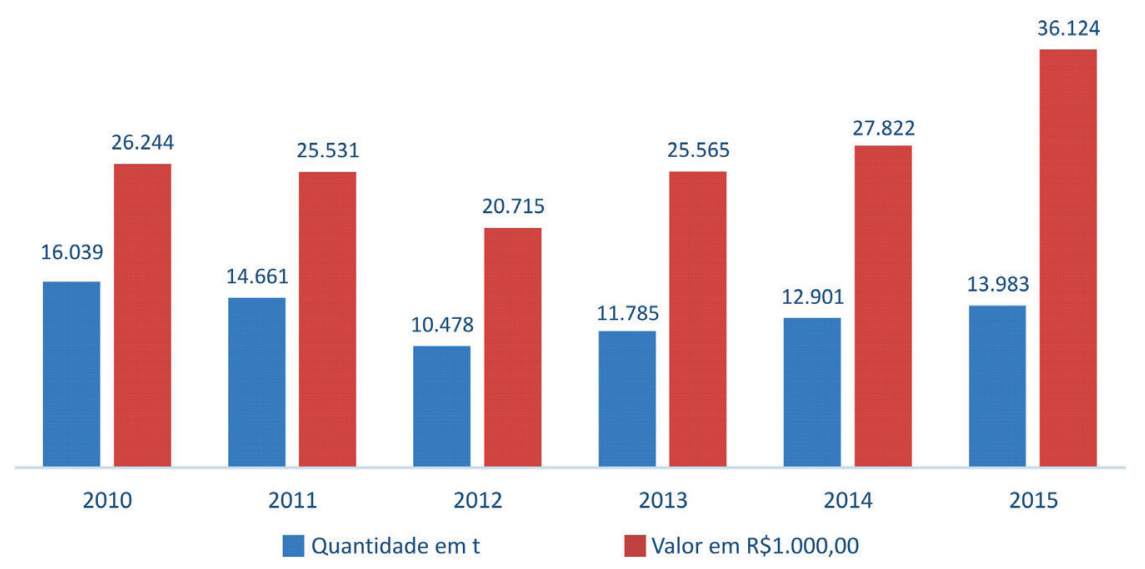

Fonte: Elaboração própria, utilizando dados do IBGE (2019).

A castanha é utilizada para variados fins: alimentício, cosmetológico e medicinal. A demanda por esse insumo decorre principalmente para atendimento do mercado interno, com ênfase no Sul do País. Assim como o açaí, a castanha é utilizada também na fabricação de cosméticos e biocosméticos como: cremes de limpeza, xampus, hidratantes, sabonetes, batons, perfumes e condicionadores. O comércio intenso desse insumo favorece a exportação para outros países, como EUA, Inglaterra, França e Alemanha.

O óleo de copaíba é extraído da Floresta Amazônica, e a região Norte detém a maior produção nacional, correspondendo a 99,66\%. O Amazonas é o maior produtor dessa matéria-prima, que no ano de 2010 teve aumento expressivo de 585 t, sendo responsável naquele ano por cerca de $92,76 \%$ do total produzido no País.

Houve queda na produção nos anos de 2011 e 2012 no estado do Amazonas, em decorrência da baixa produtividade dos municípios amazonenses por causa dos ciclos naturais das espécies e do clima na região. Além disso, sua produção é restrita, com pouco enfoque no aumento da sua produtividade.

Ademais, houve aumento significativo da produção entre 2013 e 2015 (Figura 4). O município que detém a maior produção dessa matéria-prima é Apuí, seguido de Parintins, Purus e Lábrea.

A Figura 4 mostra a quantidade produzida e o valor da produção no estado do Amazonas, indicando a queda e recuperação tanto da produção quanto do valor da produção. 
Figura 4. Evolução da produção do óleo de copaíba no estado do Amazonas.

Quantidade produzida e valor do produto da extração do óleo de copaíba no Amazonas - 2010 a 2015

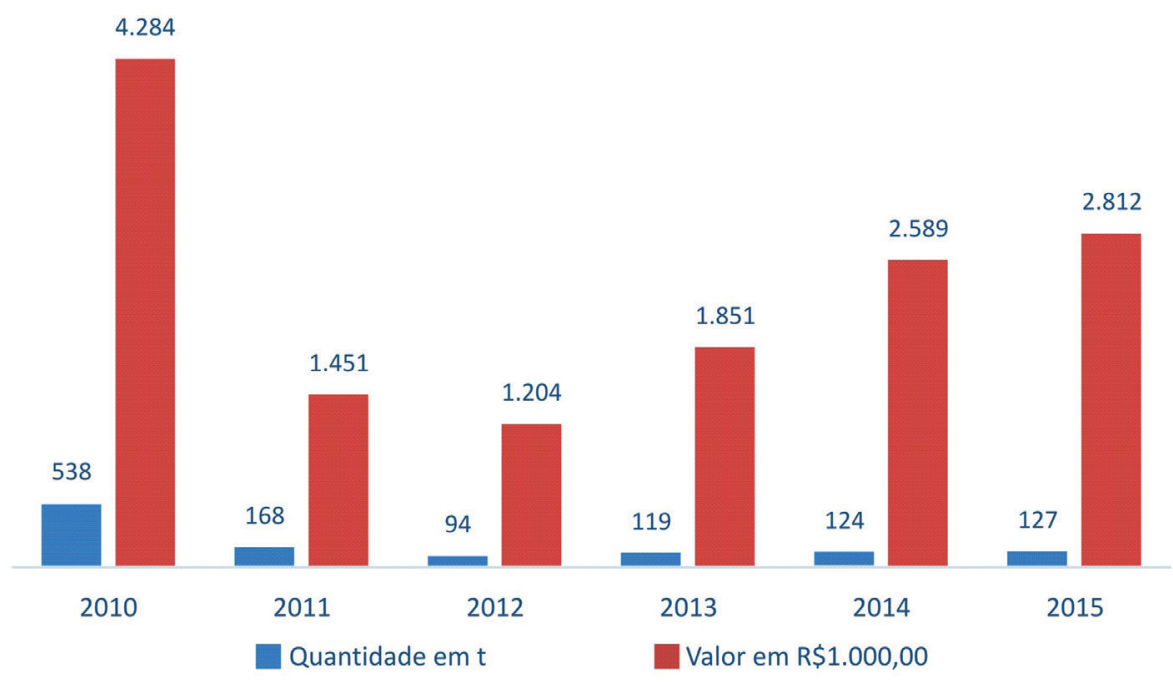

Fonte: Suframa (2019).

O óleo ou resina de copaíba é utilizado no mercado em diversos segmentos. Em sua forma medicinal é anti-inflamatório e antibiótico, com propriedades curativas e cicatrizantes. Por conseguinte, a indústria de cosméticos e fármaco-químicos utiliza a copaíba na fabricação de seus produtos, a qual possui alta capacidade de fixação em perfumes, também é utilizada em cremes pós-barba, em condicionadores, xampus, perfumes, colônias, águas de banho e perfumes para o ambiente, auxilia no tratamento da caspa; e na área fármaco-química, no tratamento da acne.

A produção de cremes de beleza, cremes nutritivos e loções tônicas na indústria de transformação do Amazonas, entre 2010 e 2015, mostrou a formação de uma grande quantidade de estoques, resultado do excesso de oferta apresentado nesse segmento.

No ano de 2011, verificou-se uma drástica diminuição da quantidade produzida com relação ao ano anterior. Esse fato acarretou crescimento nos anos seguintes e uma tendência de recuperação do mercado de HPPC do estado, mas que não atingiu os altos níveis apresentados em 2010, resultado da crise enfrentada entre 2013 e 2014 pelo PIM, que só conseguiu se recuperar em 2015, quando atingiu níveis de produção e de venda maiores que os de 2010 (Figura 5).

Na Figura 6, referente também à produção de cremes e loções, nota-se uma tendência de crescimento das vendas. Essencialmente, com exceção do ano de 2012, que apresentou um percentual significativo de vendas voltadas para o mercado local, as vendas seguem uma tendência comum à dinâmica do PIM, direcionando esses produtos de beleza principalmente ao mercado nacional. 
Figura 5. Quantidade produzida e vendas totais de cremes de beleza, cremes nutritivos e loções tônicas da indústria de transformação amazonense - 2010-2015.

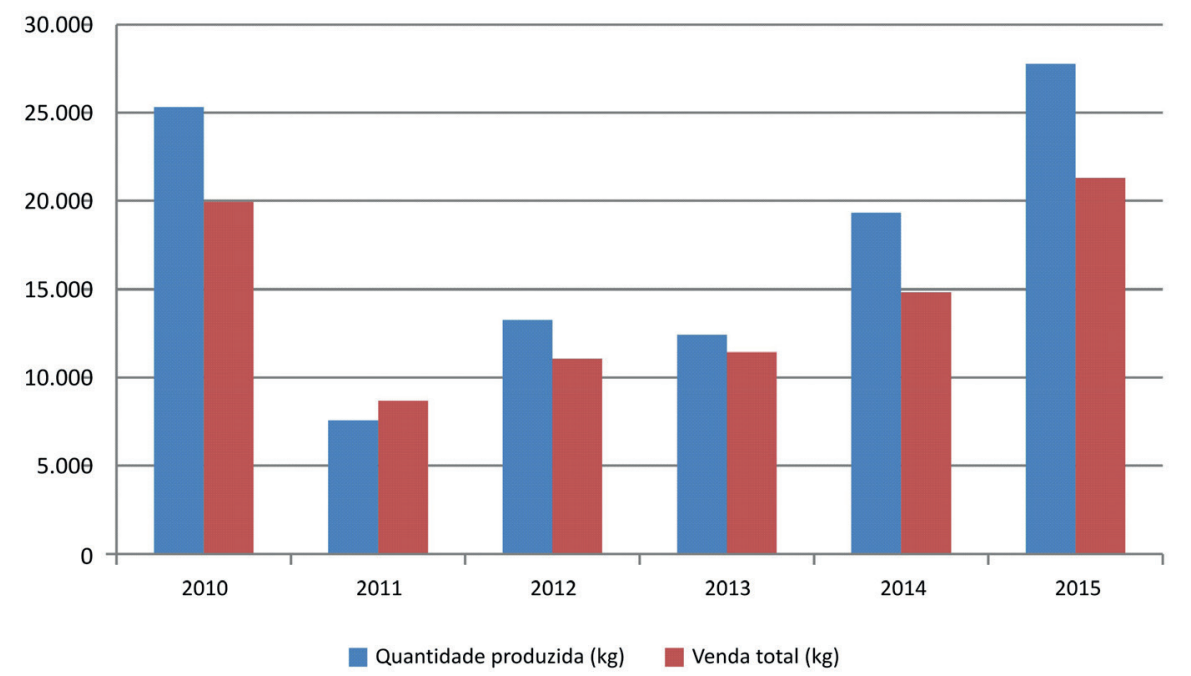

Fonte: Suframa (2019)

Figura 6. Quantidade vendida em níveis local, nacional e internacional de cremes de beleza, cremes nutritivos e loções tônicas da indústria de transformação amazonense - 2010-2015.

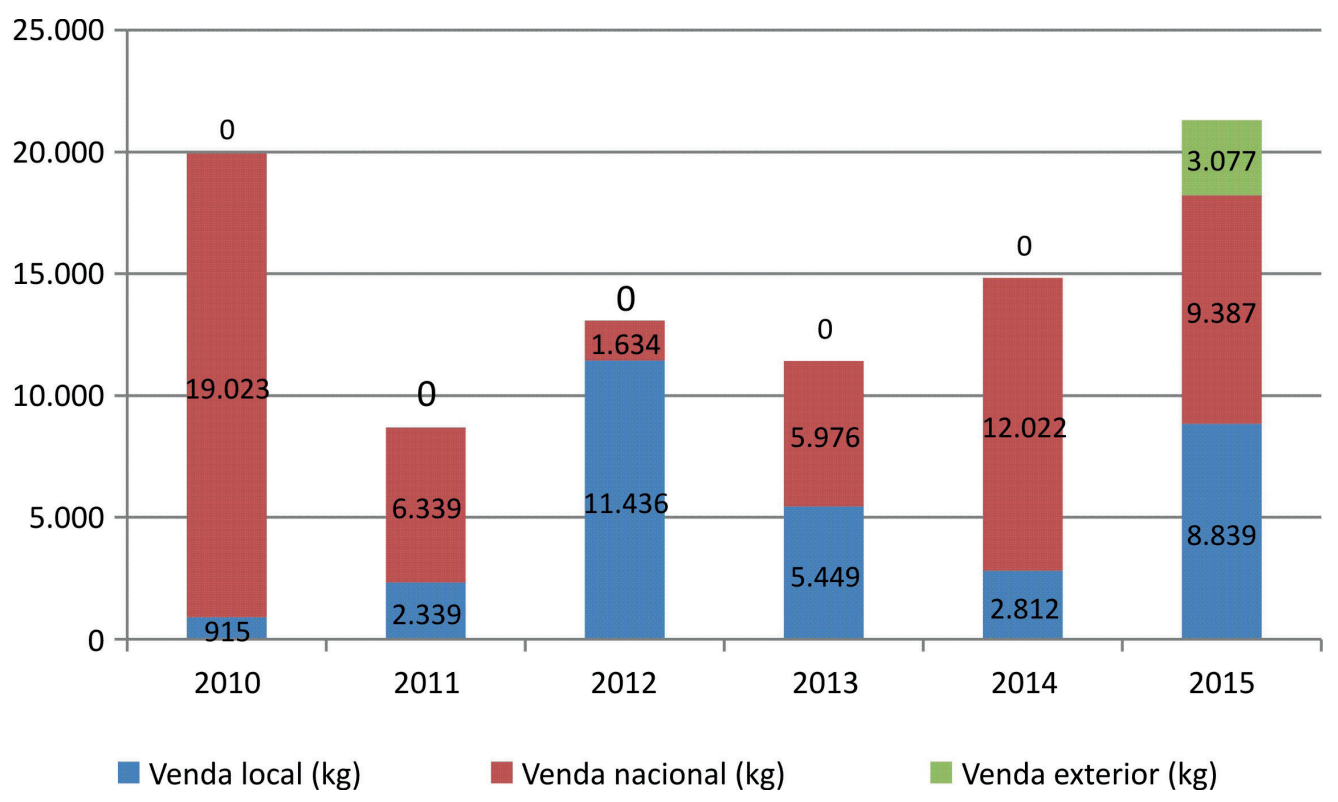

Fonte: Suframa (2019).

As vendas para o mercado externo precisam apresentar um diferencial significativo com relação aos produtos vendidos no mercado doméstico. No ano de 2015, as vendas para esse mercado específico atingiram cerca de $23,14 \%$ do total comercializado, esse percentual expressivo pode estar ligado à incorporação crescente de insumos regionais a artigos cosméticos e à consequente expansão do mercado de produtos naturais - Biocosméticos. 
Na sequência, assim como a produção de cremes e loções tônicas na indústria amazonense, a produção de xampus no estado também apresentou excesso de oferta, no entanto menor do que o apresentado na produção anterior; apenas 12,21\% da produção total, entre 2010 e 2015, foi convertida em estoques.

Como mostra a Figura 7, a produção de xampus no ano de 2011 foi a única, dentro do período analisado, que apresentou um percentual de venda total acima da quantidade total produzida no ano. $\mathrm{O}$ ano de 2012 recebe destaque entre os demais por apresentar uma produção total de $509.760 \mathrm{~kg}$, muito acima da média dos demais anos: $17.900 \mathrm{~kg}$.

Figura 7. Quantidade produzida e venda total de xampus.

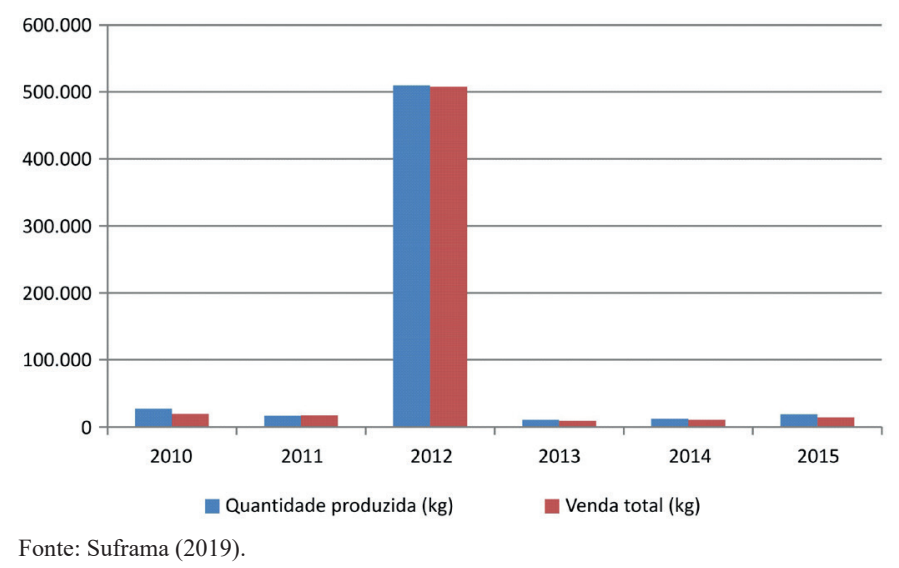

Em consequência de a quantidade produzida ter sido muito superior à média estadual, o ano de 2012 também obteve o maior percentual de vendas, 99,6\% da sua produção total foi comercializada nesse ano, o maior percentual do setor no período observado. Como pode ser analisado na Figura 8, a venda desse produto entre 2010 e 2011 destinou-se ao mercado nacional e, a partir de 2012, seguiu uma tendência voltada para o mercado amazonense. As vendas para o mercado exterior só iniciaram no ano de 2015 , representando aproximadamente $10 \%$ do total de vendas.

Figura 8. Quantidade de xampus vendida em níveis local, nacional e internacional - 2010-2015.

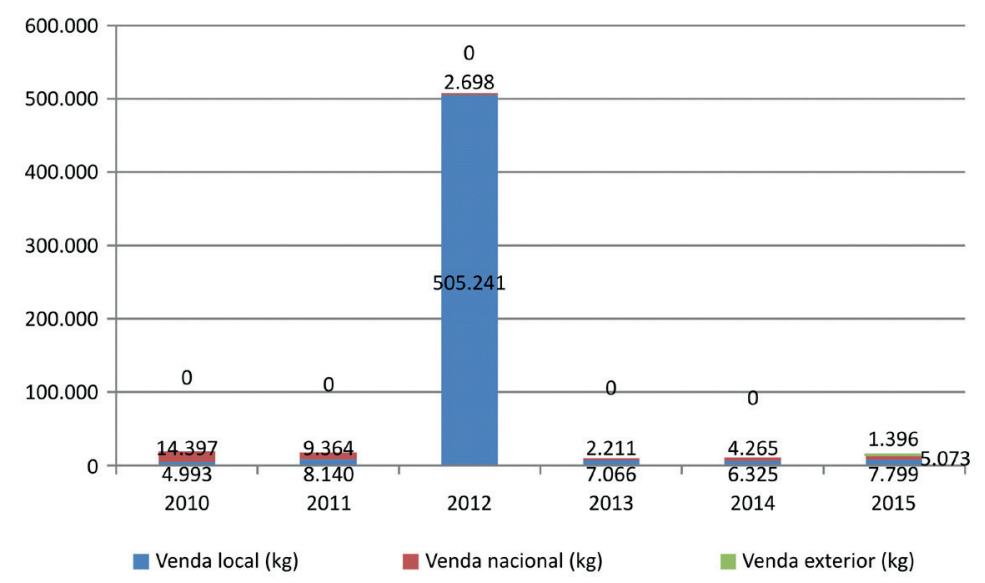

Fonte: Suframa (2019). 
A produção de sais perfumados e de outras preparações para banhos, assim como os demais produtos, também apresentou tendência à formação de estoques. No ano de 2011 foi observada uma queda drástica da produção desses artigos cosméticos, uma produção total cerca de $74 \%$ menor que a calculada no ano anterior. Nos anos seguintes, entre 2012 e 2014, a produção manteve uma média de aproximadamente 9,405 kg, e em 2015 voltou a apresentar tendência de crescimento (Figura 9).

Figura 9. Quantidade produzida e venda total de sais perfumados e de outras preparações para banhos da indústria de transformação amazonense - 2010-2015.

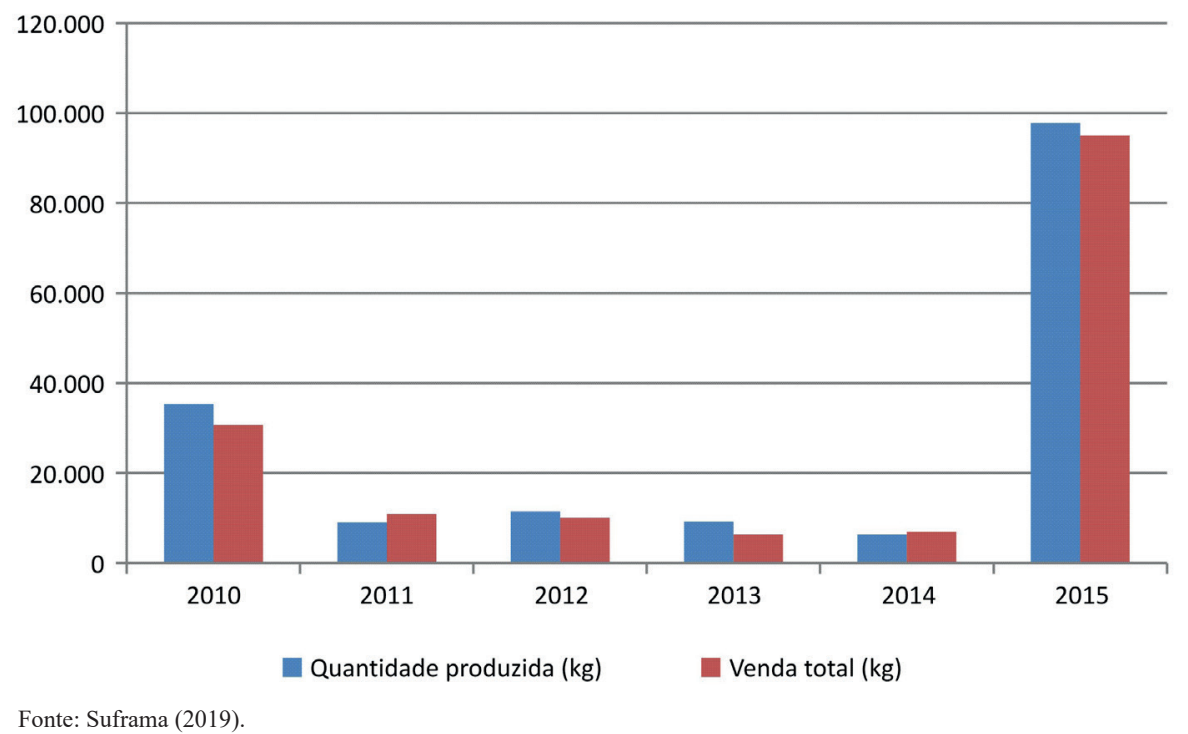

Nota-se que os sais perfumados atendem, em sua maioria, a demanda local, em que são evidenciados os dados de vendas, com exceção do ano de 2011, que teve o cenário nacional como maior público demandante desses produtos (Figura 10).

A produção de biocosméticos caracteriza-se pela procedência de mais de $90 \%$ de insumos de origem natural advindos da Floresta Amazônica. A presente pesquisa buscou descrever a produção dos biocosméticos, por meio do levantamento bibliográfico de artigos encontrados em sites, como: Google acadêmico, Scielo e Econopapers, nos quais se verificou que a maior parte dos biocosméticos encontra-se relacionada aos cosméticos convencionais, sem a distinção de insumos.

A pesquisa buscou, por meio de dados provenientes da Produção Nacional da Extração Vegetal e da Silvicultura do IBGE, descrever acerca da produção e do valor (por mil), além da evolução da produção ao longo dos anos de 2010 a 2015, mediante a escolha dos principais insumos utilizados na fabricação de bioprodutos, como castanha, açaí e copaíba. 
Figura 10. Quantidade vendida em níveis local, nacional e internacional de sais perfumados e de outras preparações para banhos da indústria de transformação amazonense - 2010-2015.

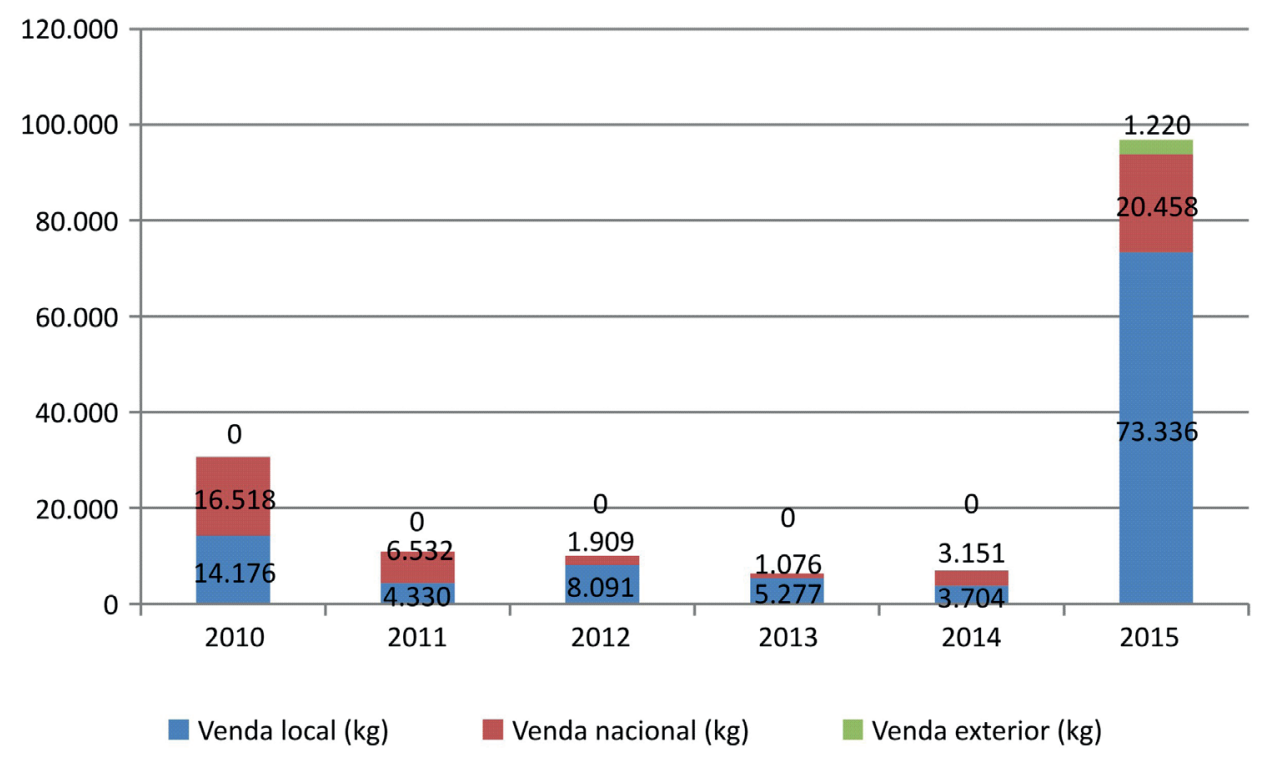

Fonte: SUFRAMA (2019).

Por outro lado, para verificar o impacto dos biocosméticos para a indústria de transformação amazonense, buscaram-se dados originários da Suframa, analisando indústrias do segmento de cosméticos; refletiu-se sobre a importância para esse setor pelo total produzido e o total de vendas nos cenários local, nacional e internacional. Observa-se que a indústria de cosméticos no PIM tem pouco impacto em relação a outros setores da indústria de transformação.

Além disso, os resultados encontrados mostram que a indústria de cosméticos amazonense possui sua produção para atender o mercado local, ou seja, o próprio estado do Amazonas, com exceção dos cremes de beleza, cremes nutritivos e loções tônicas, com maior parte da produção para atender o mercado nacional.

Ademais, os dados obtidos e a pesquisa bibliográfica realizada mostram as implicações da produção dos biocosméticos para o desempenho econômico do estado. O impacto gerado pela bioindústria de cosméticos ainda é pouco explorado, dado principalmente à questão do uso dos insumos amazônicos, que ainda é insuficiente para atender ao comércio em larga escala de produção.

Outrossim, durante nossa pesquisa, encontrou-se certa dificuldade em desagregar os dados sobre os insumos utilizados na fabricação de biocosméticos, visto que estes se encontram inseridos no mesmo segmento de cosméticos convencionais de origem sintética, fato que dificultou o campo de estudo. Diante disso, é recomendado que os biocosméticos devam estar classificados em outra categoria dentro dos cosméticos, a qual corrobore e facilite estudos mercadológicos, pesquisas de caráter científico e políticas públicas voltadas para a regionalização da economia no estado do Amazonas dentro dessa cadeia produtiva. 
Por fim, não há a procedência das matérias-primas utilizadas na fabricação dos bioprodutos nem o percentual de regionalização desses insumos, por exemplo: a quantidade necessária para a fabricação do creme para pele à base de açaí ou de copaíba, que ocasiona tanto para o mercado quanto para os empresários um desincentivo em relação a esses produtos, devido a pouquíssimos dados relacionados a essa questão e à concentração de informações quanto à origem dos insumos pelos empresários desse segmento de mercado, que diminui a abrangência de consumidores interessados por produtos naturais

\section{Conclusão}

A partir dos dados analisados verificou-se que a produção de açaí teve $13 \%$ de correlação com a produção de xampus. Já a castanha teve um percentual de $42,5 \%$ de correlação em relação aos cremes de beleza, cremes nutritivos e loções tônicas e um percentual de 34\% em relação aos de sais perfumados e outras preparações para banhos. Por fim identificou-se a correlação de $43 \%$ na produção de copaíba em relação à produção de cremes.

A bioindústria de cosméticos no Amazonas apresenta dificuldades na regularidade do aprovisionamento das matérias-primas utilizadas na fabricação de bioprodutos, visto que o cultivo desses insumos apresenta sazonalidade, como é o caso do açaí, da castanha e da copaíba. Além disso, a logística de transporte na região amazônica é outro fator que desincentiva a instalação de uma nova matriz econômica no estado em razão da dificuldade de escoamento da matéria-prima para a indústria de biocosméticos.

Observou-se, ao longo da pesquisa, que a logística de escoamento da produção extrativista tem sido um grande problema para o estado do Amazonas. Diante disso, para alavancar essa cadeia produtiva e o setor de biocosméticos compreende-se que é necessário impulsionar a saída de tais matérias-primas mediante investimento do setor público, com construções de estradas e ramais, e de portos, e também com a contribuição do setor privado por meio de empréstimos e financiamentos para os produtores rurais e empresas do setor, para investimento no desenvolvimento logístico da cadeia produtiva, propiciando a criação de postos de trabalho e o incremento à renda dos produtores.

Conclui-se, por fim, que o desempenho econômico e a produção de biocosméticos no estado ainda são incipientes devido a fatores já supracitados anteriormente. Nesse sentido, o caminho a seguir para alavancar essa produção é: investir nas comunidades produtoras do estado, a fim de diminuir os custos de logística; promover criação de usinas de beneficiamento em municípios com alta produtividade dos insumos usados na produção de biocosméticos; investir na área de pesquisa tanto para buscar o aumento da produtividade como também a produção de novos bioprodutos oriundos da Amazônia; além disso, fomentar a comercialização local e nacional. 


\section{Referências}

ASSOCIAÇÃO BRASILEIRA DA INDÚSTRIA DE HIGIENE PESSOAL, PERFUMARIA E COSMÉTICOS - ABIHPEC. Panorama do setor - Higiene pessoal, perfumaria e cosméticos. São Paulo, 2006.

ASSOCIAÇÃO BRASILEIRA DA INDÚSTRIA DE HIGIENE PESSOAL, PERFUMARIA E COSMÉTICOS - ABIHPEC. Panorama do setor 2017 - Higiene pessoal, perfumaria e cosméticos. 2018. Disponível em: https://abihpec.org.br/anuario-2018-flip/mobile/index.html $\# p=18$. Acesso em: 14 out. 2018.

BARATA, L. E. S. Economia verde: Amazônia. Ciência e Cultura, v. 64, n. 3, p. 31-35, 2012. Disponível em: http://cienciaecultura.bvs.br/pdf/cic/v64n3/a11v64n3.pdf. Acesso em: 06 mar. 2018.

BASTOS, M. F. S.; LOPES, R. H.; FIGUEIREDO, S. C. G. A competitividade sustentável do mercado amazônico. Revista Científica NAMBIQUARA, v. 3, p. 1-8, 2012. Disponível em: http://periodicos. fametro.edu.br/index.php/nanbiquara/article/view/32. Acesso em: 21 dez. 2018.

FLEURY, P. F.; WANKE, P.; FIGUEIREDO, K. F. Logística empresarial - a perspectiva brasileira. São Paulo: Atlas, 2000.

GARCIA, R.; FURTADO, J. Estudo da competitividade de cadeias integradas no Brasil: impactos das zonas de livre comércio da cadeia de cosméticos. Campinas: UNICAMP, 2002. 100 p. (Nota Técnica Final).

IBGE. Sistema IBGE de Recuperação Automática - Sidra. Produção Nacional da Extração Vegetal e da Silvicultura. 2019. Disponível em: https://sidra.ibge.gov.br/tabela/289\#resultado. Acesso em: 25 jun. 2020 .

IBGE. Subsecretaria de Arrecadação e Atendimento. Classificação Nacional das Atividades Econômicas - CNAE. 2015. Disponível em: www.cnae.ibge.gov.br/?view=estrutura\&tipo=cnae\&versao_clas$\mathrm{se}=7.0 .0 \&$ versao_subclasse $=9.1 .0$. Acesso em: 19 fev. 2019 .

ISAAC, G. E. A. O desenvolvimento sustentável do setor de cosmético e o comportamento do consumidor final frente aos cosméticos sustentáveis. 2016. 139 f. Dissertação (Mestrado) - Centro Universitário das Faculdades Associadas de Ensino, São João da Boa Vista. Disponível em: https://cutt.ly/ ahvsPvH. Acesso em: 15 fev. 2019.

JUDICE, V. M. M.; BAÊTA, A. M. C. Clusters em bio-indústria e biotecnologia em Minas Gerais - habitats construídos de inovação, competitividade e desenvolvimento regional. Revista Gestão \& Tecnologia, v. 1, p. 155-170, 2002. Disponível em: http://revistagt.fpl.edu.br/get/article/view/107. Acesso em: 15 fev. 2019 .

LIMA, S. P. M. de. Cadeia produtiva dos biocosméticos no Amazonas: da terra ao laboratório, do laboratório a indústria e deste mercado. 2011. 198 f. Dissertação (Mestrado em Geografia) - Universidade Federal do Amazonas, Manaus. Disponível em: https://tede.ufam.edu.br/handle/tede/4001. Acesso em: 15 fev. 2019.

LOPES, R. H. Demanda global e produção local de matéria-prima para a indústria de biocosméticos no Pólo Industrial de Manaus. In: INTERNATIONAL CONFERENCE ON INDUSTRIAL ENGINEERING MANAGEMENT, MATURITY AND CHALLENGES OF THE PRODUCTION ENGINEERING: COMPANY COMPETITIVENESS, WORK CONDITIONS, ENVIRONMENT, 17., 2011, Belo Horizonte. Tecnological innovation and intelectual property: production engineering challenges in Brazil consolidation in the world economic scenario. São Paulo: ABEPRO, 2011. v. 1. 
LOPES, R. H.; CAVALCANTE, K. V. A Amazônia como apelo de mercado e estoque de matéria prima para a indústria de biocosméticos: ficção ou realidade?. In: ENCONTRO NACIONAL DE ENGENHARIA DE PRODUCAO, 30.; INTERNATIONAL CONFERENCE ON INDUSTRIAL ENGINEERING MANAGEMENTE, MATURITY AND CHALLENGES OF THE PRODUCTION ENGINEERING, 16. 2010, São Carlos. Maturidade e desafios da engenharia de produção: competitividade das empresas, condições de trabalho, meio ambiente. São Paulo: ABEPRO, 2010.

LYRIO, E. S.; FERREIRA, G. G.; ZUQUI, S. N.; SILVA, A. G. Recursos vegetais em biocosméticos: conceito inovador de beleza, saúde e sustentabilidade. 2011. 5 f. Trabalho de Conclusão de Curso (Monografia) - Curso de Graduação Tecnológica em Estética, Centro Universitário de Vila Velha, Vila Velha. Disponível em: http://www.naturezaonline.com.br/natureza/conteudo/pdf/10_LyrioESetal_4751. pdf. Acesso em: 06 mar. 2018.

MARSHALL, A. Princípios de economia: tratado introdutório. São Paulo: Abril Cultural, 1982. v. 1, p. 231-238.

MIGUEL, L. M. A biodiversidade na indústria de cosméticos: contexto internacional e mercado brasileiro. 2012. 259 f. Tese (Doutorado) - Universidade de São Paulo, São Paulo. Disponível em: http://www. teses.usp.br/teses/disponiveis/8/8136/tde-12062013-112427/pt-br.php. Acesso em: 6 mar. 2018.

MIGUEL, L. M. Experiência sobre a utilização da biodiversidade: as bioindústrias de cosméticos na Amazônia brasileira. Trabalho apresentado no $12^{\circ}$ Encuentro de Geógrafos da América Latina - EGAL, 2009, Montevideo/Uruguai.

PORTER, M. E. Estratégia competitiva: técnicas para análise de indústrias e da concorrência. Rio de Janeiro: Campus, 1986.

REVILLA, J. Plantas da Amazônia: oportunidades econômicas e sustentáveis. Manaus: SEBRAE: INPA, 2001. $405 \mathrm{p}$.

SERVIÇO BRASILEIRO DE APOIO ÀS MICRO E PEQUENAS EMPRESAS - SEBRAE; ESCOLA SUPERIOR DE PROPAGANDA E MARKETING - ESPM. Cosméticos à base de produtos naturais. Relatório completo. Brasília, DF, 2008. (Série Mercado, Estudos de Mercado). Disponível em: http:// www.biblioteca.sebrae.com.br. Acesso em: 10 jan. 2019.

SUFRAMA. Indicadores de desempenho do Pólo Industrial de Manaus (2003-2008). Manaus, 2009.

SUFRAMA. Indicadores industriais. Manaus, 2019.

VARIAN, H. A. L. R. Microeconomia: princípios básicos. Rio de Janeiro: Elsevier, 2006. v. 7, Cap. 23, p. 430. 
